\begin{tabular}{|c|c|c|c|c|c|}
\hline JRL & Vol. 13 & No.2 & Hal. 116-137 & $\begin{array}{c}\text { Jakarta, } \\
\text { Desember 2020 }\end{array}$ & $\begin{array}{c}\text { p-ISSN : 2085.38616 } \\
\text { e-ISSN : 2580-0442 }\end{array}$ \\
\hline
\end{tabular}

\title{
KONSEP IMBAL JASA LINGKUNGAN UNTUK KEBERLANJUTAN SUMBERDAYA AIR DAS CIDANAU
}

\author{
${ }^{1}$ Dwindrata Basuki Aviantara*, ${ }^{2}$ Fuzi Suciati \\ ${ }^{1}$ Gd. 820 Geostech PUSPIPTEK Serpong, 15314, Provinsi Banten \\ *Penulis korespondensi: dwindrata.basuki@bppt.go.id
}

\begin{abstract}
Abstrak
DAS Cidanau, satu-satunya ekosistem rawa pegunungan di Pulau Jawa, merupakan sumber air baku yang penting bagi Provinsi Banten, khususnya dalam memenuhi kebutuhan kawasan industri serta penduduk Kota Cilegon. Meskipun DAS Cidanau merupakan kawasan Cagar Alam namun perambahan serta penggundulan hutan yang marak menyebabkan ancaman terhadap keberlanjutan penyediaan air. Masyarakat hulu yang mengandalkan sumberdaya alam serta masyarakat hilir yang mengandalkan air memerlukan penyelesaian memuaskan kedua belah pihak. Karena masing-masing memiliki kepentingan maka perlu dibangun mutual relationship antar keduanya. Melalui mekanisme Imbal Jasa Lingkungan (IJL) terbentuk hubungan imbal balik menguntungkan antara masyarakat hilir selaku penerima manfaat atas air dengan masyarakat hulu selaku penjamin kelangsungan ekosistem hulu untuk daerah resapan air. Skema IJL memiliki dampak positif terhadap perbaikan keanekaragaman hayati, fungsi ekologik serta sosio-ekonomik. Keberterimaan nilai layak atas air diukur dengan kesediaan untuk membayar yang merupakan kesepakatan bersama antara penyedia jasa dan pengguna jasa dalam IJL. Guna menjamin pelaksanaan IJL secara transparan diperlukan kelembagaan pemangku kepentingan yang terdiri dari kelompok tani, lembaga swadaya masyarakat serta pemerintah daerah. Karya tulis ini bertujuan menarasikan lesson learned penerapan konsep IJL antara PT Krakatau Titra Industri dengan masyarakat hulu DAS Cidanau yang dimediasi oleh Forum Komunikasi DAS Cidanau.
\end{abstract}

Kata kunci: Imbal Jasa Lingkungan, willingness to pay, sumberdaya air, keberlanjutan. 


\title{
PAYMENT CONCEPT FOR ENVIROMENTAL SERVICE TO SUSTAIN CIDANAU WATER RESOURCE
}

\begin{abstract}
The Cidanau Watershed, the only swamp forest ecosystem available in Java Island, is an important source of raw water in Banten Province, especially for industrial areas and residents of Cilegon City. Although the Cidanau Watershed is a Nature Reserve, however, encroachment and deforestation have threatened the sustainability of water availability. The needs of the upstream communities who rely on natural resources and the need on water for the downstream communities require a satisfactory solution for both parties. Because each has particular interest, it is necessary to build a mutual relationship between the two. Implementing Payment for Environmental Service (PES) mechanism, a beneficial reciprocal relationship will establish between the downstream communities as water users and the upstream communities as the guarantor for sustainability of the upstream ecosystem as water catchment areas. The PES scheme has a positive impact on the improvement of biodiversity, ecological functions and socio-economics. The acceptance on appropriate value of water is measured by willingness to pay. The latter is a mutual agreement between service providers and the users. In order to guarantee the transparancy on the implementation of PES implementation then Institutional stakeholders consisted of farmer groups, non-government organizations and local governments is needed. This paper is aimed at describing lesson learned from the implementation of PES between PT Krakatau Titra Industri with upstream community of Cidanau watershed that was mediated by Forum Komunikasi DAS Cidanau.
\end{abstract}

Keywords: Payment for Environmental Services, willingness to pay, water resource, sustainability. 


\section{PENDAHULUAN}

Air merupakan kebutuhan semua mahluk hidup. Telah diketahui bersama bahwa di alam 97\% air merupakan air asin, baik sebagai air laut maupun air tanah. Dari 3\% air tawar yang tersisa hanya sekitar $1 \%$ yang dapat digunakan untuk kebutuhan mahluk hidup karena 99\% merupakan air tanah dalam dan air beku yang berada di kutub bumi. Seiring perubahan iklim global terjadi pula kelangkaan air sehingga pada tanggal 22 Maret 1993 dicanangkan sebagai Hari Air Sedunia oleh Persatuan BangsaBangsa (United Nations Tanpa Tahun).

Beberapa wilayah Indonesia juga terjadi kelangkaan air, terutama pada musim kering. Di sejumlah tempat terjadi kesulitan pemenuhan air bersih karena mengeringnya air tanah maupun sungai. Sedangkan kebutuhan kuantitas air dengan kualitas baik terus meningkat karena pertumbuhan populasi penduduk. Selain faktor perubahan iklim yang mengubah curah hujan penurunan daya simpan air juga karena kerusakan sumberdaya alam, terutama akibat kegiatan penggundulan hutan (Pirard et al. 2014). Penggundulan hutan telah mengakibatkan peningkatan volume air larian serta kerusakan agregat tanah. Selain itu perubahan fungsi bentang lahan atau tataguna lahan juga memperparah hilangnya daya simpan tanah atas air, misal karena merubah hutan menjadi areal persawahan.

Kota Cilegon - Provinsi Banten merupakan sebuah kota industri di mana terdapat tidak kurang dari 120 buah industri beroperasi dengan total investasi setidak bernilai \$25 milyar (Amaruzaman dkk. 2017). Bahkan $80 \%$ industri kimia nasional berada di Kota Cilegon tersebut (Badan Pusat Statistik Kota Cilegon 2019). Untuk memenuhi kebutuhan air industri dan domestik wilayah tersebut mengandalkan pasokan air yang berasal dari Daerah Aliran Sungai (DAS) Cidanau.

DAS Cidanau dengan luas area 22.620 ha merupakan daerah tangkapan air yang secara administratif berada di sebagian wilayah Kabupaten Serang dan Kabupaten Pandeglang. Untuk wilayah Kabupaten Serang mencakup 5 kecamatan (meliputi 33 desa) sedangkan Kabupaten Pandeglang hanya 1 kecamatan (meliputi 4 desa). Dengan curah hujan tahunan sekitar $2.650 \mathrm{~mm}$ maka kapasitas daerah tangkapan air DAS cidanau adalah sekitar 600 juta meter kubik. Sebagai wilayah tangkapan air DAS Cidanau merupakan sumber air baku yang sangat penting bagi Provinsi Banten, khususnya di wilayah bagian barat di mana terdapat kawasan industri dari berbagai jenis. Kebutuhan debit air untuk kepentingan industri tersebut minimal adalah 1,3 $\mathrm{m}^{3} /$ det. Selain untuk keperluan industri sekitar 30 liter/det air DAS Cidanau dimanfaatkan oleh PDAM Kota Cilegon untuk penyediaan air bersih bagi penduduk Kota Cilegon. Diperkirakan pemanfaatan air yang berasal dari DAS Cidanau tidak lebih dari $6 \%$ kapasitas maksimum yang dapat diberikan oleh DAS Cidanau 
tersebut.

Kemampuan DAS Cidanau dalam menyediakan kebutuhan air bagi industri dan domestik menghadapi tekanan akibat perubahan curah hujan serta tutupan lahan. Perubahan tutupan lahan tersebut berkaitan erat dengan pemanfaatan sumberdaya alam di wilayah hulu oleh masyarakat hulu guna memenuhi kebutuhan hidup. PT Krakatau Tirta Industri sebagai perusahaan pengelola dan penyedia air bersih untuk industri dan domestik Kota Cilegon perlu mencari penyelesaian yang memenuhi semua harapan. Dengan konsep Imbal Jasa Lingkungan perusahaan tersebut masih mampu untuk menyediakan kebutuhan air bersih dan pada saat yang sama mampu mencegah kerusakan ekosistem hulu akibat perubahan tutupan lahan. Paper ini menyajikan lesson learned hasil penerapan konsep Imbal Jasa Lingkungan tersebut. Tujuan dari penulisan ini adalah menjelaskan lesson learned hasil penerapan konsep Imbal Jasa Lingkungan (environmental service payment) dalam pengelolaan sumberdaya air guna mempertahankan keberlanjutan fungsinya.

\section{METODE}

Dalam menyusun tulisan ini digunakan metode penelusuran informasi sekunder yang diperoleh dari jurnal (nasional dan internasional), laporan teknis, textbook, buku pegangan (handbook) serta sejumlah sumber lainnya yang dapat diperoleh dari laman internet.

\section{PEMBAHASAN}

\subsection{PERMASALAHAN DAS CIDANAU}

Persoalan mendasar yang menyebabkan tekanan terhadap DAS Cidanau sebagai ekosistem penyedia air adalah fluktuasi curah hujan, perubahan tutupan Iahan, serta peningkatan kebutuhan air. Keadaan tersebut menimbulkan persoalan terutama dalam upaya pemenuhan kebutuhan air bagi industri dan domestik khususnya pada saat musim kering di mana debit air yang mengalir adalah minimal. Fluktuasi curah hujan dengan perioda kering yang lebih panjang akibat proses perubahan iklim mengakibatkan batas kritik kebutuhan air minimal semakin didekati. Nisbah $\mathrm{Q}_{\max } / \mathrm{Q}_{\min }$ sebesar 31,8 pada perioda 1982 - 1992 telah turun menjadi 15,0 pada pengamatan tahun 1997. Kebutuhan debit minimal sebesar 1,3 $\mathrm{m}^{3} / \mathrm{det}$ menjadi terancam untuk dapat dipenuhi dengan adanya masalah perubahan tutupan lahan dan penurunan kualitas lingkungan DAS Cidanau seperti erosi yang mencapai 140 ton/ha/tahun serta laju sedimentasi sebesar $76 \mathrm{~cm} /$ tahun (setara dengan 480.000 ton/tahun)(FKDC 2007). Perubahan tutupan lahan berdasarkan pengamatan citra satelit pada tahun 1997 dan 2004 ditunjukkan pada Gambar 2. Dari gambar tersebut tampak bahwa pada tahun 2004 telah terjadi pengurangan areal kebun campuran, lahan kering, dan semak akibat peningkatan luas areal persawahan.

Berdasarkan Surat Keputusan Menteri Kehutanan No 3586 Tahun 2014 menetapkan sebagian dari 
DAS Cidanau yang luasnya 3542,70 ha merupakan kawasan Cagar Alam (DLHK Provinsi Banten 2018). Cagar Alam dengan nama Rawa Danau tersebut merupakan satu-satunya ekosistem rawa pegunungan yang ada di Pulau Jawa. Cagar Alam Rawa Danau selain merupakan kawasan endemik dengan keanekaragaman hayati setidaknya 131 spesies eko sistem rawa (Amaruzaman dkk. 2017) juga merupakan kawasan tandon air. Cagar Alam Rawa Danau menerima masukan aliran air dari 18 anak sungai serta hanya memiliki satu keluaran sungai yaitu Sungai Cidanau yang mengalirkan air dari kawasan Cagar Alam Rawadanau menuju ke hilir. Di bagian hilir Sungai Cidanau terpasang pipa pengambilan air milik PT Krakatau Tirta Industri. Pipa ini mengalirkan air yang diambil dari sungai tersebut untuk diolah pada fasilitas pengolahan air bersih yang berjarak $28 \mathrm{~km}$ di daerah Krenceng (merupakan wilayah administratif Kota Cilegon). Pola aliran air dalam DAS Cidanau ditunjukkan pada Gambar 3.

Meskipun kawasan cagar alam menurut peraturan menteri yang berlaku merupakan daerah yang terlarang untuk digunakan sebagai tempat kegiatan pertanian, perkebunan, dan pemukiman namun kenyataannya sebagian kawasan Cagar Alam Rawadanau pernah dirambah hingga luasan 847 ha. Akibat beban limbah domestik serta penggunaan pupuk dalam kegiatan persawahan di dalam kawasan tersebut telah menurunkan mutu air yang akan diolah oleh PT Krakatau Tirta Industri.

Beban tersebut telah mengakibatkan terjadinya ledakan alga serta tumbuhnya gulma air yang memberikan konsekuensi peningkatan biaya pengolahan penyediaan air bersih. Pembalakan liar yang terjadi di kawasan hulu DAS Cidanau juga semakin memperparah keadaan ekosistem DAS Cidanau karena mengakibatkan sedimentasi serta ancaman debit kritikal pada musim kering. Dengan pertumbuhan penduduk Kota Cilegon sebesar $2,66 \%$ ditambah berkembangnya industri di wilayah tersebut menyebabkan nilai air yang dihantarkan oleh DAS Cidanau menjadi bernilai ekonomi tinggi. Keberlanjutan industri serta kebutuhan air bersih masyarakat di Kota Cilegon sangat bergantung kepada debit dan kualitas air yang mengalir di dalam DAS Cidanau. 


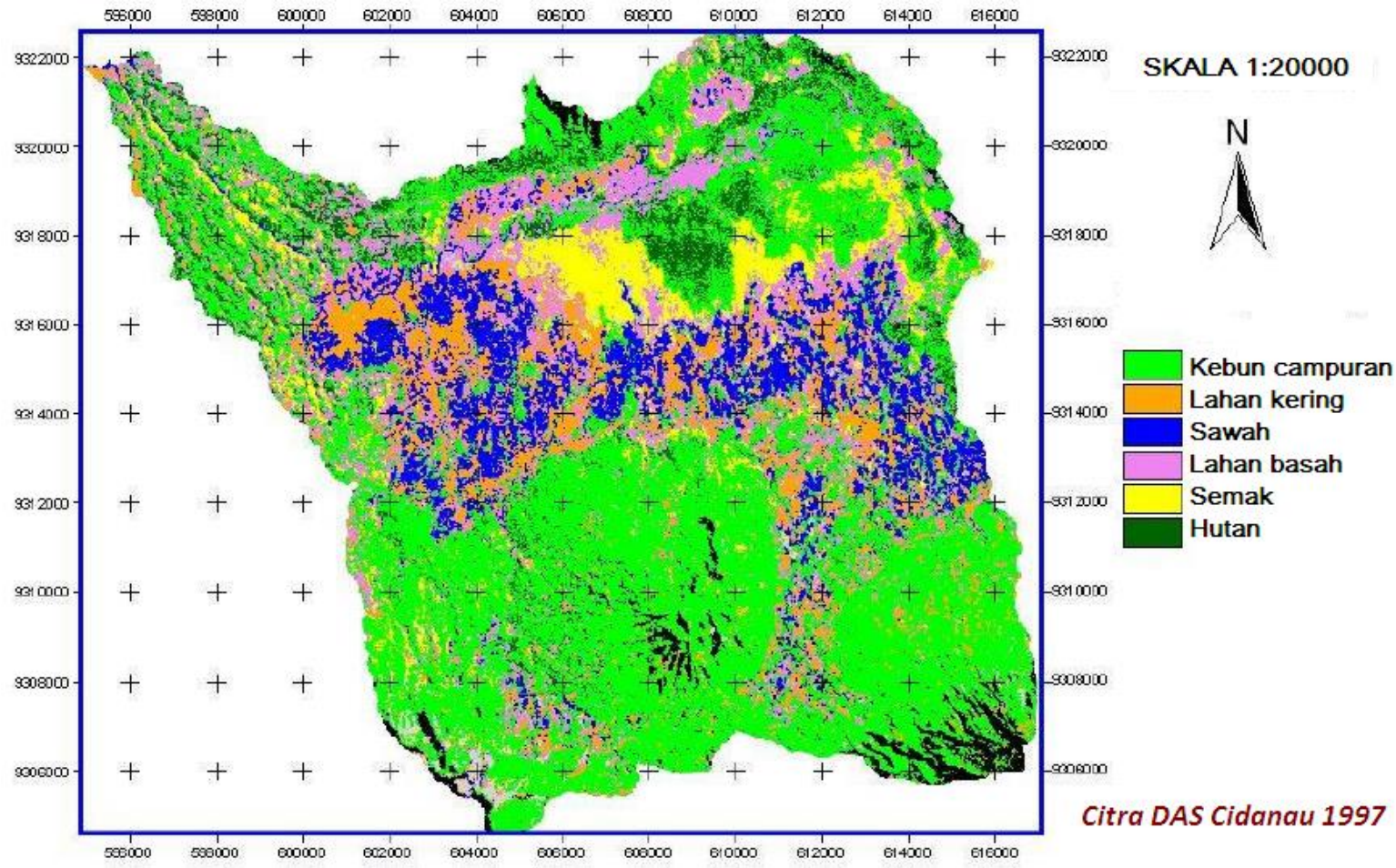

Gambar 1. Perubahan tutupan Iahan DAS Cidanau hasil foto citra satelit tahun 1997 


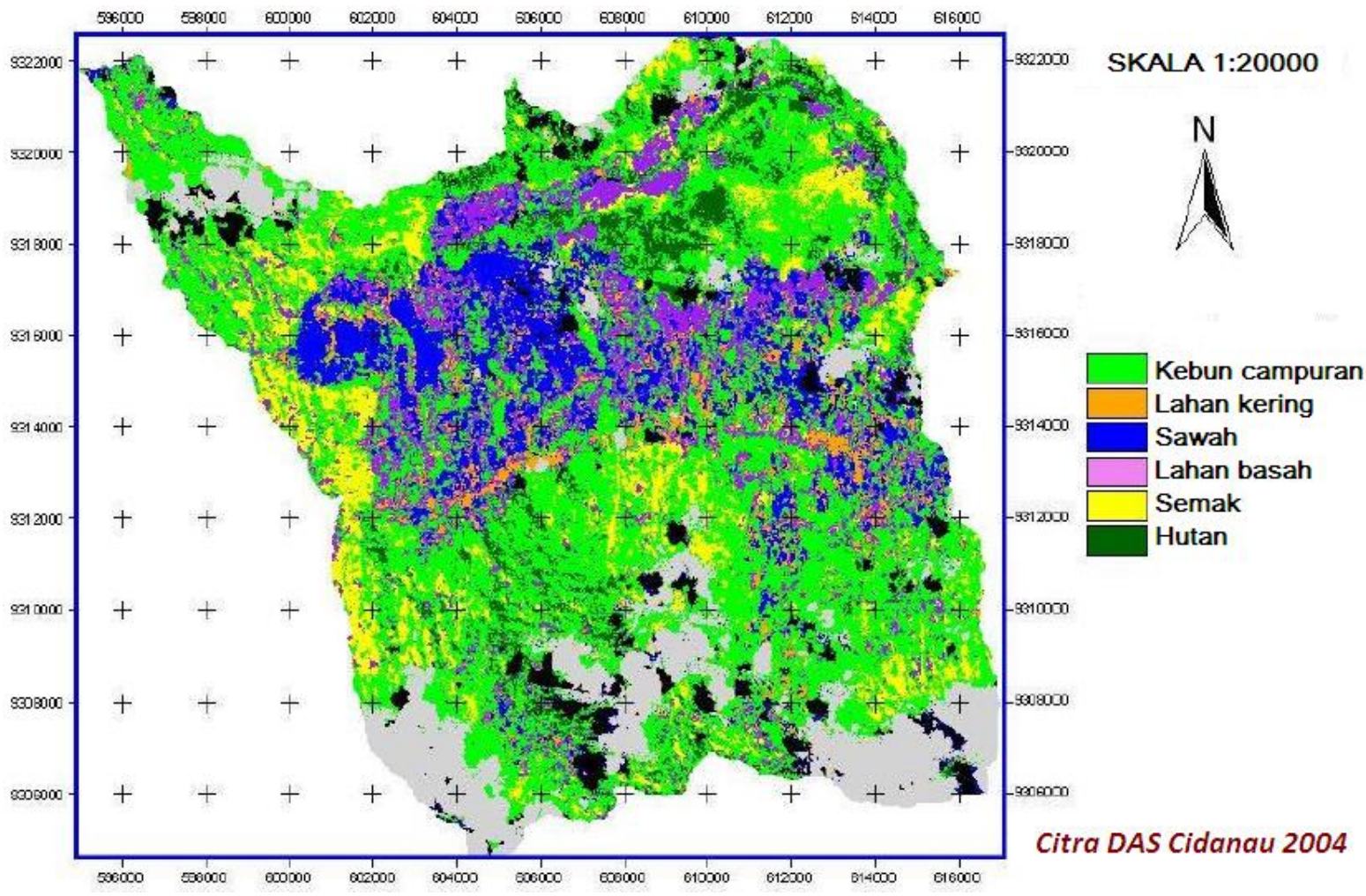

Gambar 2. Perubahan tutupan Iahan DAS Cidanau hasil foto citra satelit tahun 2004 


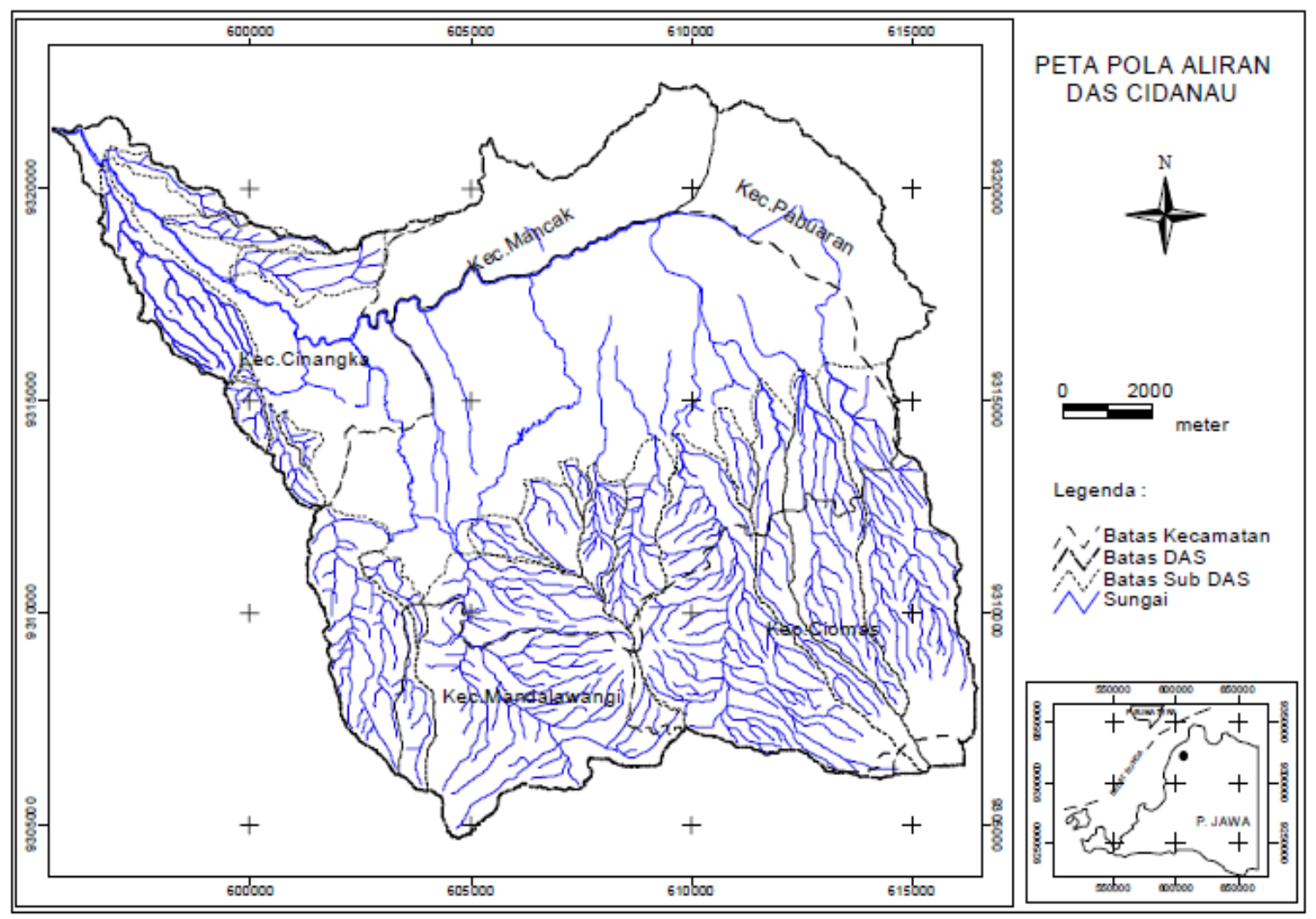

\subsection{SITUASI MASYARAKAT WILAYAH HULU DAS CIDANAU}

Berbeda dengan penduduk yang hidup di wilayah hilir masyarakat hulu DAS Cidanau lebih mengandalkan kehidupan dengan bergantung kepada ekosistem DAS Cidanau (Hayati dkk. 2010). Sebagai contoh bersawah, menebang kayu serta memetik buah-buahan. Kegiatan bercocok tanam serta penebangan kayu memengaruhi perubahan ekosistem DAS Cidanau terutama bila dilakukan dengan cara yang tidak berwawasan lingkungan. Hal tersebut ditambah lagi dengan sejumlah pencetus atau faktor yang air pada DAS Cidanau memicu terjadinya degradasi Cagar Alam Rawa Danau sebagaimana diperlihatkan pada Gambar 4 (FKDC Tanpa Tahun).

Pada saat ini diperkirakan 4300 ha bagian hulu DAS Cidanau dalam keadaan kritik yang memerlukan penanganan optimal. Di sisi lain keberlanjutan Cagar Alam Rawadanau sebagai tandon air sangat ditentukan oleh keadaan tatahidrologi di wilayah hulu. Karena masing-masing pihak memiliki kepentingan, yakni masyarakat hilir membutuhkan air untuk pembangunan sosial dan ekonomi sedangkan masyarakat hulu membutuhkan pendapatan ekonomi untuk kesejahteraan hidup maka 
perlu dibangun mutual relationship yang memenuhi kebutuhan keduanya. Melalui mekanisme imbal jasa lingkungan (Payment for Environmental Services) dapat dibangun hubungan imbal balik menguntungkan antara masyarakat hilir sebagai pemanfaat air dengan masyarakat hulu sebagai penjamin kelangsungan ekosistem daerah hulu sebagai kawasan tandon air.

\subsection{KONSEP IMBAL JASA LINGKUNGAN (PAYMENT FOR ENVIRONMENTAL SERVICES)}

Alam tidak dapat dinilai (valued) akan tetapi jasa (service) yang diberikan olehnya kepada manusia dapat dinilai (Namirembe et al. 2017). Konsep mengenai Imbal Jasa Lingkungan telah diperkenalkan pada tahum 1970 (Megawanto 2018). Konsep tersebut muncul berkaitan dengan fakta bahwa perubahan keanekaragaman hayati memengaruhi fungsi ekosistem yang menyokong jasa bagi kepentingan manusia. Artinya ekosistem memberikan "jasa" seperti provisioning, supporting dan regulating serta cultural bagi kepentingan manusia (Vasseur \& Siron 2019). Dengan memahami keterkaitan tersebut diharapkan masyarakat tergerak untuk melakukan konservasi sumberdaya alam.
Terminologi Payment for Environmental Services (PES) muncul pertama kali dalam dokumen Millennial Ecosystem Assessment pada tahun 2005 (Megawanto 2018) yang melaporkan bahwa separuh jasa lingkungan yang diberikan oleh alam untuk keperluan manusia telah mengalami kemerosotan karena pemanfaatan yang dilakukan secara tidak berkelanjutan.

Secara sederhana konsep Imbal Jasa Lingkungan (IJL) adalah sebagaimana disajikan pada Gambar 5. Cakupan jasa lingkungan dapat penyangkut apa saja yang berkaitan fungsi atau peran ekosistem seperti aspek hidrologik, keanekaragaman hayati, perosotan karbon (carbon sequestration) atau yang menyangkut nilai-nilai keindahan (scenic values). Terdapat tiga kelompok yang terlibat dalam mekanisme IJL, yakni penyedia (seller) jasa lingkungan, penerima manfaat (buyer) atas jasa lingkungan yang diberikan oleh penyedia jasa lingkungan serta perantara (intermediary) yang menjadi jembatan dalam mekanisme IJL. Perantara diperlukan bilamana antara penyedia dan penerima manfaat tidak memungkinkan untuk melakukan transaksi atau bisnis secara langsung. Namun bilamana antara keduanya memungkinkan untuk dilakukan transaksi atau bisnis secara langsung maka peran dari perantara dapat dihilangkan. 


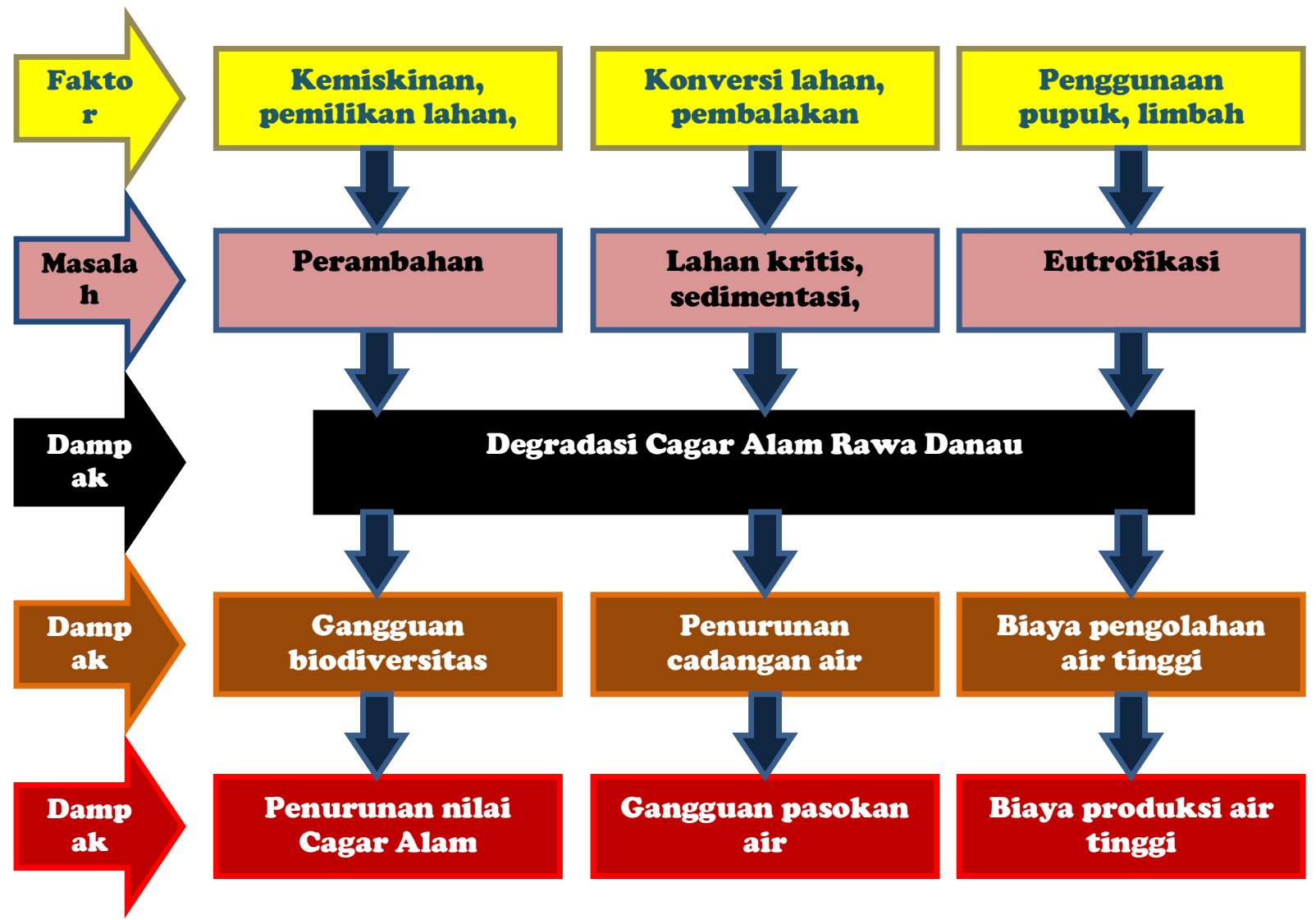

Gambar 4. Faktor pencetus, masalah hingga dampak persoalan DAS Cidanau 


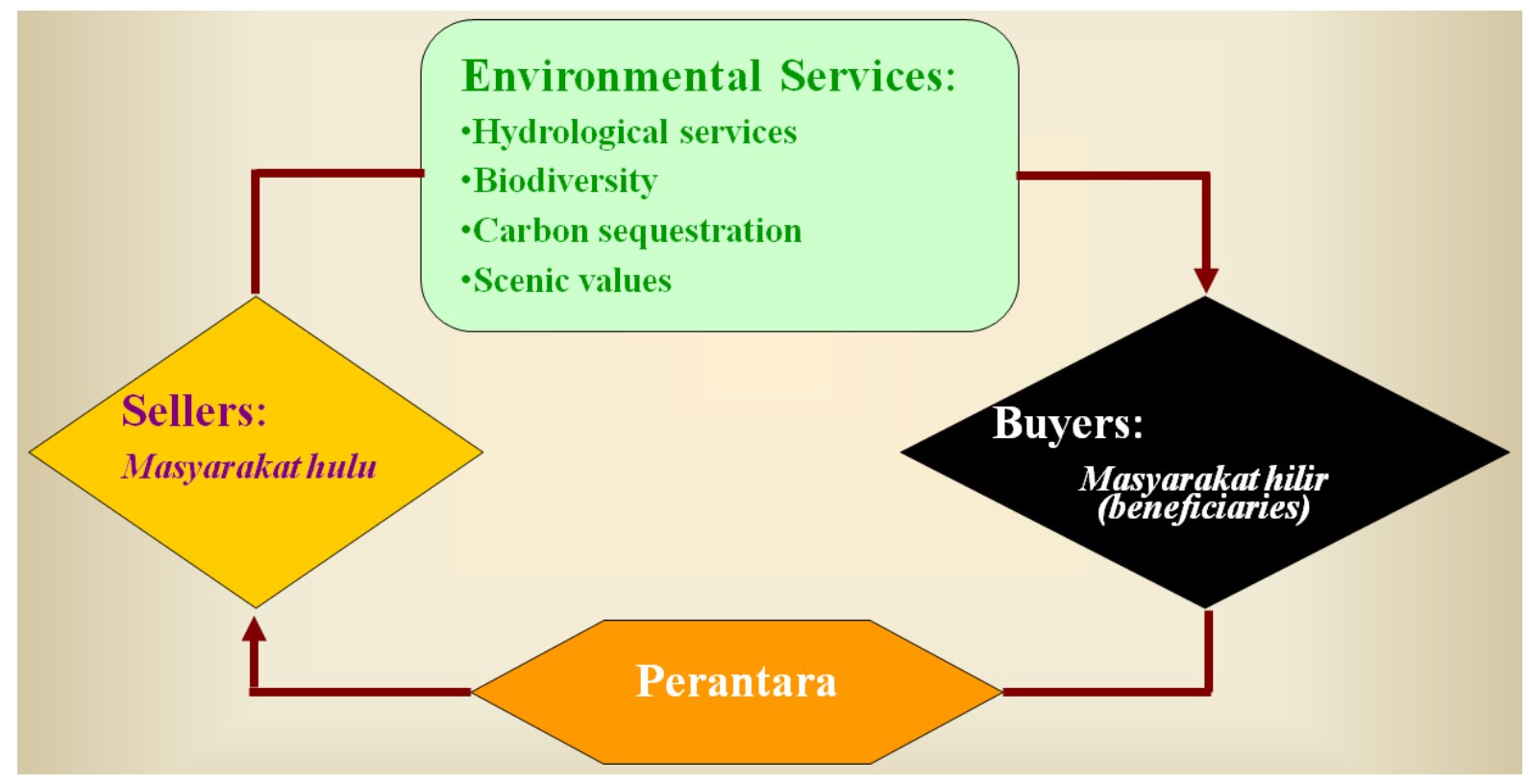

Gambar 5. Konsep Imbal Jasa Lingkungan

Untuk kasus DAS Cidanau pada saat konsep IJL diujicobakan dalam proyek percontohan peran dari perantara sangat diperlukan. Hal ini dikarenakan sumberdaya manusia dari kelompok-kelompok tani yang ada belum memadai untuk mengelola sebuah proyek. Bahkan hingga saat ini masih terdapat kecenderungan bahwa perkembangan peningkatan kemampuan SDM berproses lambat (Tacconi et al. 2013). Hal demikian memiliki potensi terhadap timbulnya hambatan bagi keberlangsungan IJL itu sendiri. Oleh sebab itu dalam pelaksanaan IJL diperlukan juga upaya pemberdayaan masyrakat untuk memahami tidak saja konsep mengenai IJL namun juga bagaimana menerapkan konsep tersebut.

\subsection{PERKIRAAN KEBUTUHAN AIR KOTA CILEGON}

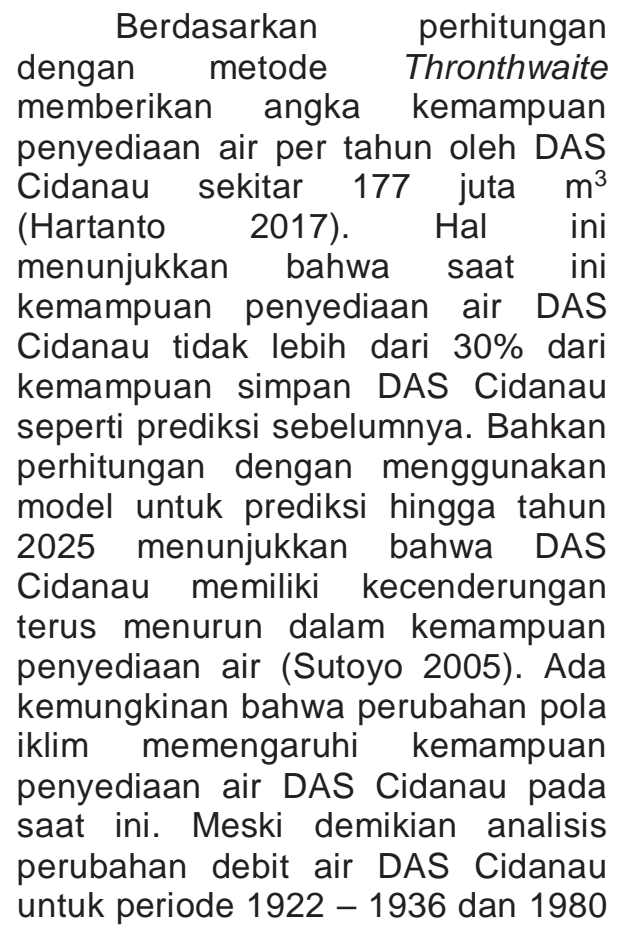


- 2001 menghasilkan pola sebagaimana disajikan pada Gambar 6 (Priyanto 2006). Pola tersebut menunjukkan bahwa untuk musim kering (bulan Juni November) kemampuan DAS Cidanau dalam memberikan air adalah serupa. Hasil perhitungan memberikan $Q_{\min }=5 \mathrm{~m}^{3} / \mathrm{s}, Q_{\max }=20$ $\mathrm{m}^{3} / \mathrm{s}$, serta Q rataan $=13 \mathrm{~m}^{3} / \mathrm{s}$ di mana pada musim kering dapat mencapai $\mathrm{Q}<1 \mathrm{~m}^{3} / \mathrm{s}$.

Proyeksi menggunakan pendekatan dugaan lebih (over estimation) kebutuhan air Kota Cilegon pada periode 1990 - 2010 ditunjukkan pada Gambar 7. Ekstrapolasi berdasarkan periode tersebut memperkirakan kebutuhan air pada 2030 mendekati $10 \mathrm{~m}^{3} / \mathrm{s}$. Namun berdasarkan perhitungan model (Sutoyo 2005) dengan parameter lebih rinci memberikan kebutuhan adalah separuh daripada yang diperkirakan menurut Gambar 6. Oleh sebab itu secara kasar kebutuhan air kawasan Cilegon baik untuk keperluan industri, masyarakat maupun kegiatan lainnya (misal pertanian dan perkebunan) diperkirakan berada dalam kisaran 5 - $10 \mathrm{~m}^{3} / \mathrm{s}$. Dengan meningkatnya permintaan atas air di kawasan Cilegon, khususnya yang terkait dengan pertumbuhan industri, jelas bahwa debit minimum merupakan persoalan yang harus diantisipasi. Terutama dengan menimbang musim kering yang periodenya semakin panjang serta adanya fenomena global warming yang mengubah iklim global. Dampaknya adalah keadaan lingkungan yang lebih parah, khususnya terhadap persoalan global lainnya, yaitu water scarcity. 


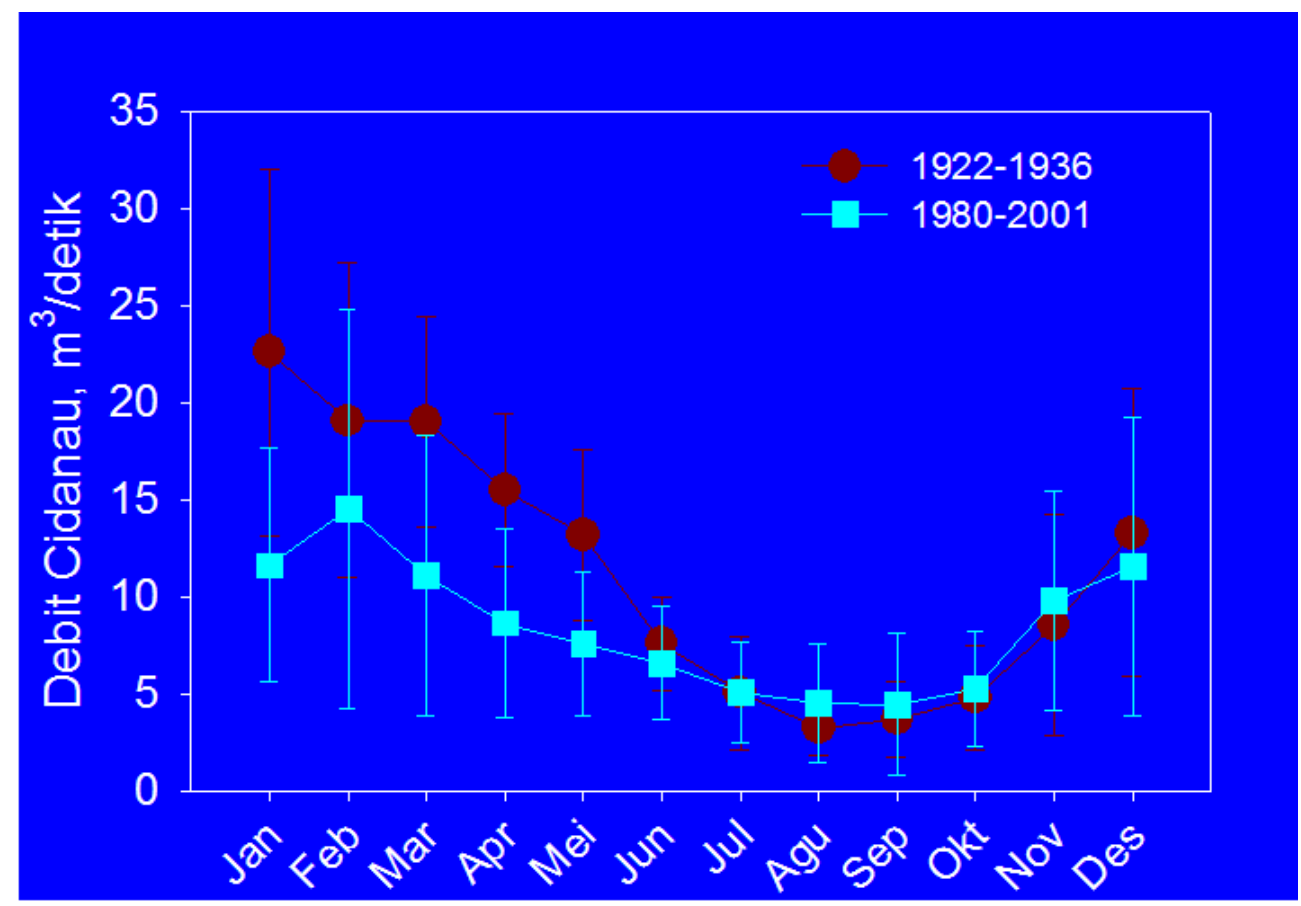

Gambar 6. Pola perubahan debit Das Cidanau periode 1922-1936 dan 1980_ 2001 


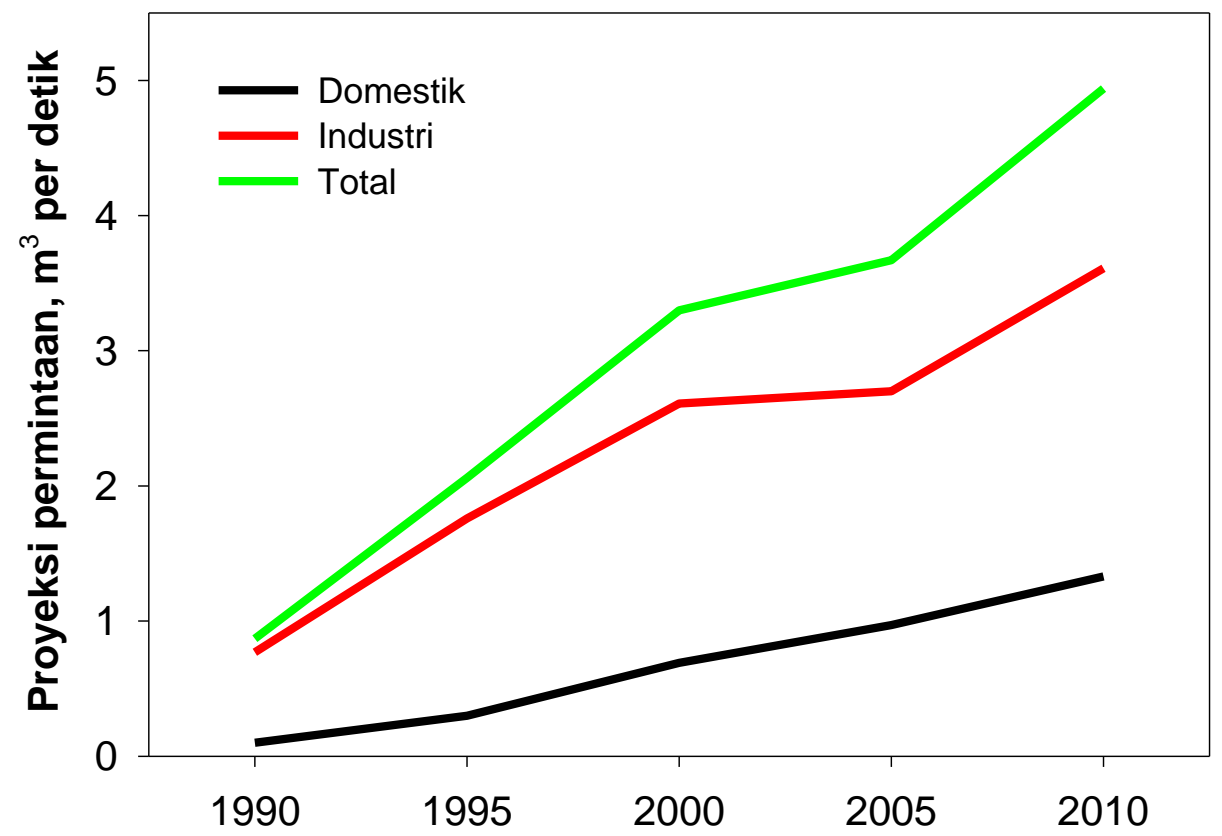

Gambar 7. Proyeksi permintaan air kawasan Cilegon periode 1990 - 2010 


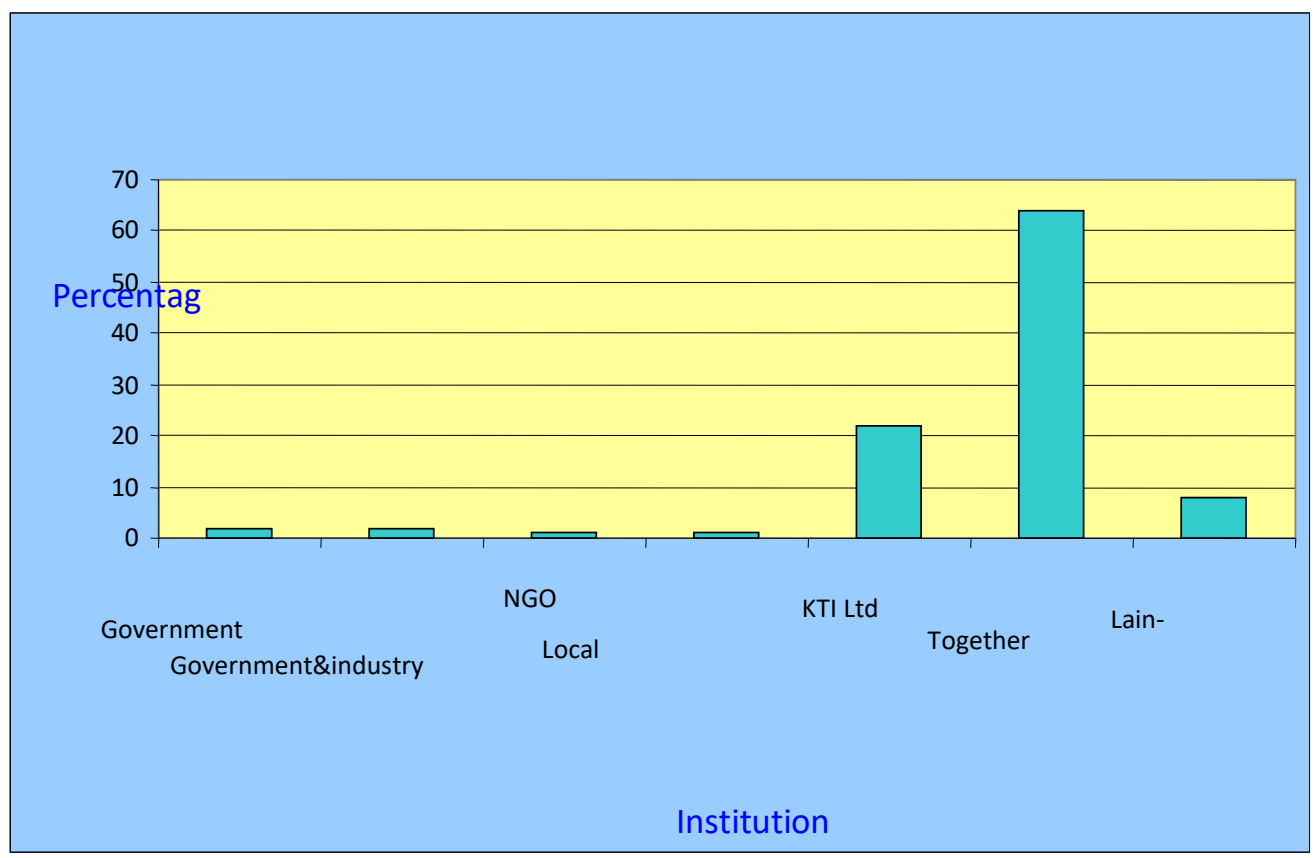

Gambar 8. Sebaran keberterimaan para pihak atas nilai air DAS Cidanau

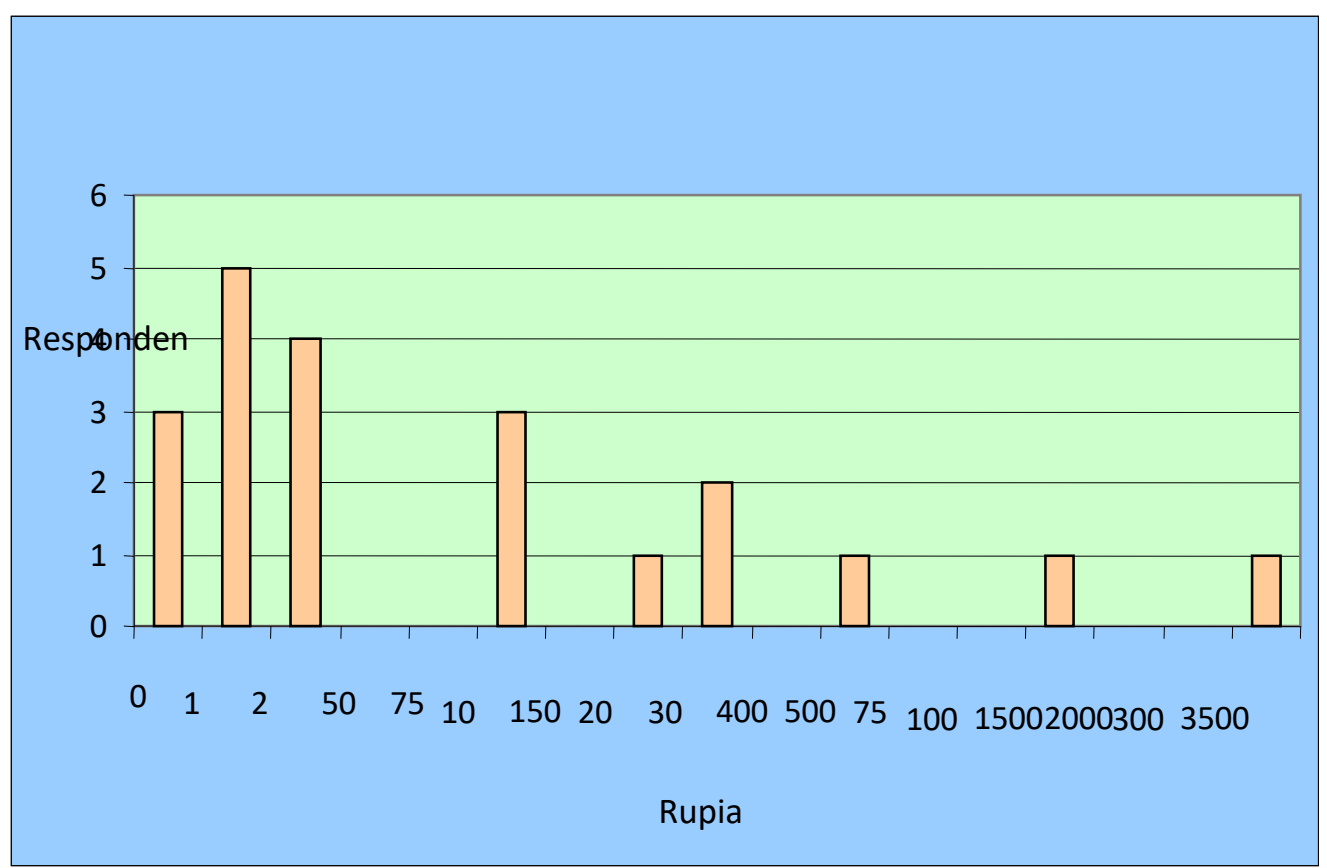

Gambar 9. Sebaran kesediaan membayar (willingness to pay) per meter 
kubik air

\subsection{WILLINGNESS TO PAY ATAS NILAI AIR}

Untuk

mengetahui

keberterimaan (acceptability) atas nilai air yang layak untuk dijadikan dasar pelaksanaan IJL maka perlu digali informasi mengenai hal tersebut dari para pemangku kepentingan. Sebuah studi mengenai hal tersebut (Van de Sand 2004) kepada para pihak yang mempunyai kepentingan dengan keberlanjutan DAS Cidanau memberikan angka tengah data (median) kesediaan untuk membayar (willingness to pay) sebesar Rp.168,untuk setiap meter kubik air. Sebaran keberterimaan para pihak serta kesediaan untuk membayar atas nilai air masing-masing disajikan pada Gambar 8 dan 9.

Dengan sebaran kesediaan membayar atas nilai air tersebut telah dikonversikan ke dalam bentuk potensi luasan lahan sebesar 200 ha yang dapat dijadikan sebagai areal konservasi di kawasan DAS Cidanau. Dalam konteks pelaksanaan IJL disepakati bahwa untuk setiap $10 \mathrm{~m} \times 10 \mathrm{~m}$ luasan lahan di tanam minimal 5 tanaman keras. Dengan demikian dalam 1 ha luasan lahan konservasi setidaknya terdapat 500 buah tanaman keras (Munawir \& Vermeulen 2007).

\subsection{KELEMBAGAAN IMBAL JASA LINGKUNGAN}

Guna menerapkan konsep IJL ke tataran aksi diperlukan medium perantara yang menjembatani antara service provider, dalam hal ini masyarakat hulu, dengan pihak penerima manfaat (beneficiary), dalam hal ini masyarakat hilir. Untuk kasus DAS Cidanau medium perantara ini merupakan kumpulan pemangku kepentingan yang terdiri dari perwakilan masyarakat, perwakilan industri, serta perwakilan pemerintah kota, kabupaten dan provinsi (Laila dkk. 2014). Cara pengelolaan tersebut merupakan strategi pengelolaan terintegrasi dengan konsep one river, one plan, one management (Fahrizal 2009).

Seperti yang tampak pada Gambar 10 yang menjadi medium perantara untuk mekanisme IJL DAS Cidanau merupakan suatu forum pemangku kepentingan sehingga dinamakan Forum Komunikasi DAS Cidanau (FKDC Tanpa Tahun). Peran FKDC dalam pelaksanaan IJL adalah (Rochmayanto 2012):

1) Mengelola dana hasil pembayaran jasa lingkungan dari pemanfaat (buyer) jasa lingkungan DAS Cidanau untuk rehabilitasi dan konservasi lahan di DAS Cidanau melalui lembaga pengelola jasa lingkungan DAS Cidanau.

2) Mendorong pembangunan hutan di Iahan milik oleh masyarakat dengan mekanisme pembayaran jasa lingkungan.

3) Menggalang dana dari potensial pemanfaat jasa lingkungan DAS Cidanau.

4) Mendorong pemerintah untuk melakukan pembayaran jasa lingkungan di DAS Cidanau.

Sedangkan kegiatan yang dilakukan oleh FKDC adalah (Rochmayanto 2012): 
1) Membangun kesepakatan kewenangan pengelolaan DAS Cidanau diantara stakeholder DAS Cidanau.

2) Melakukan negosiasi dengan PT. Krakatau Tirta Industri untuk pembayaran jasa lingkungan, hasil negosiasi dituangkan dalam naskah kesepahaman.

3) Membentuk tim ad hoc yang menangani pengelolaan pembayaran jasa sampai dengan lembaga Pengelola Jasa Lingkungan Cidanau terbentuk.

4) Mendiskusikan mekanisme pembayaran jasa lingkungan antara tim ad hoc dengan masyarakat pemilik hutan di hulu DAS Cidanau

\subsection{DAMPAK IMBAL JASA LINGKUNGAN}

Skema IJL dipandang memiliki dampak positif terhadap perbaikan keanekaragaman hayati, fungsi ekologik serta keadaan sosio-ekonomik (Suich et al. 2017). Meski demikian dampak perbaikan ekonomik tidak begitu nyata dibandingan dengan ketiga dampak lainnya.

\subsubsection{Dampak Ekologik}

Skema IJL melalui penanaman 500 pohon per hektar secara sains belum dapat menunjukkan korelasi secara langsung terhadap perbaikan ekologik, khususnya dalam hal penurunan laju sedimentasi maupun erosi DAS Cidanau. Hal ini disebabkan penanaman pohon hanya dilakukan di lahan atau pekarangan petani yang kering serta dengan luasan yang kurang memadai terhadap luasan Iahan terdegradasi penyebab erosi dan sedimentasi. Dengan laju erosi sebesar \pm 71.000 ton/tahun diperkirakan luasan lahan di wilayah hulu DAS Cidanau yang mengalami degradasi adalah 507 ha. Berdasarkan hasil studi willingness to pay yang memberikan prediksi luasan lahan 200 ha dapat dicakup dalam mekanisme IJL maka hanya 40\% lahan bermasalah yang dapat ditangani. Kenyataan bahwa luasan terkini yang terlibat dalam skema IJL DAS Cidanau tidak melebihi 50 ha maka merupakan tantangan tersendiri dalam membuat mekanisme IJL menjadi menarik bagi para petani, khususnya petani miskin. 

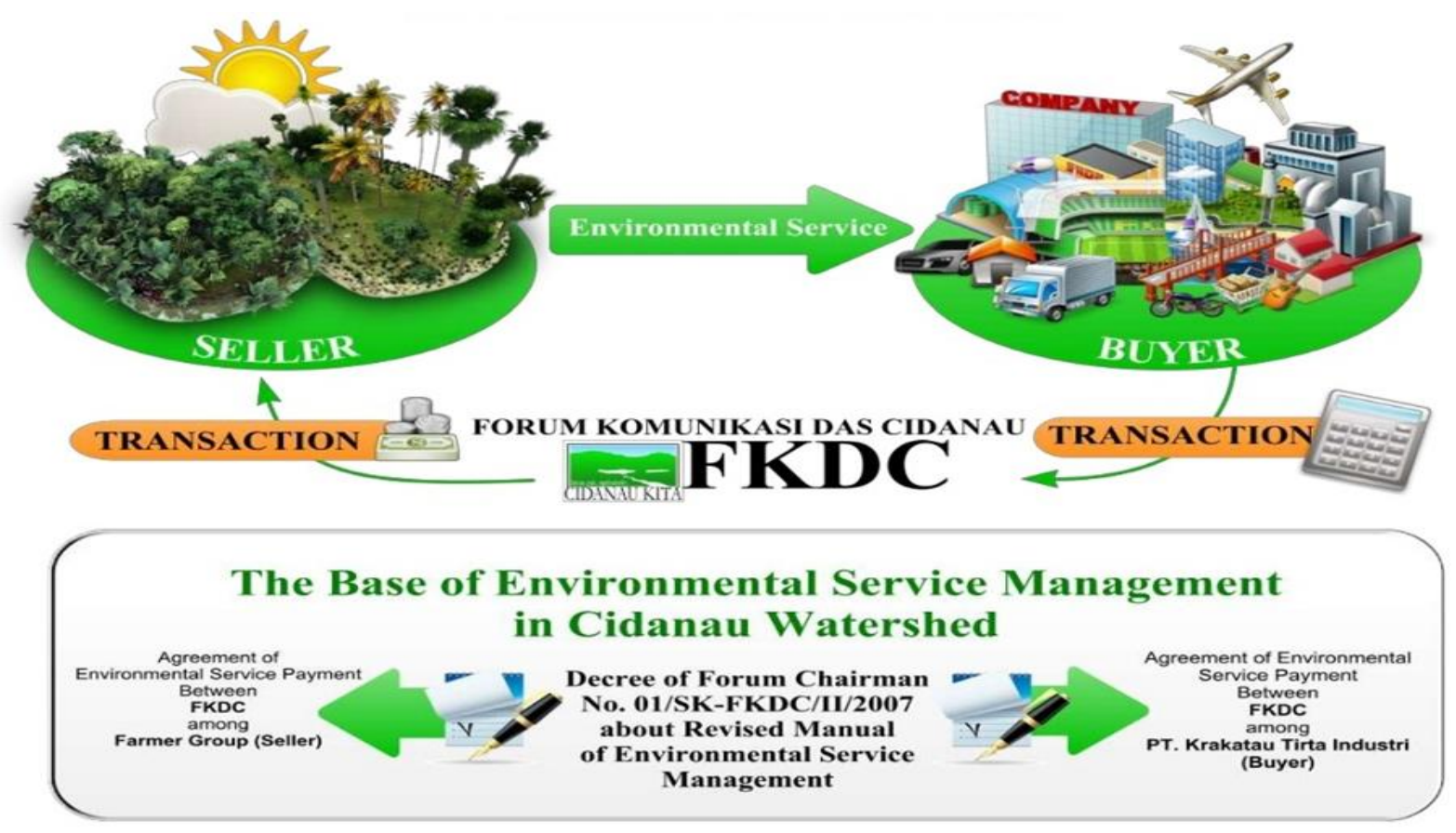

Gambar 10. FKDC sebagai medium perantara mekanisme IJL DAS Cidanau

Penurunan laju erosi dan sedimentasi lebih dipengaruhi oleh upaya pemerintah daerah dalam membangun teras atau perekayasaan lain untuk mencegah erosi. Upaya penghijauan di wilayah hulu serta penanaman pohon di wilayah Cagar Alam Rawa Danau yang pernah dirambah oleh pendatang juga memberikan pengaruh baik terhadap penurunan laju erosi dan sedimentasi. Meski demikian bila mekanisme IJL dapat diperluas dengan meningkatkan jumlah kelompok petani serta meningkatkan luasan lahan maka secara agregrat diperkirakan mampu memberikan kostribusi perbaikan ekosistem hulu DAS Cidanau.

\subsubsection{Dampak sosio-ekonomik}

Skema IJL memberikan dampak positif bagi perkembangan sistem agribisnis serta perbaikan pendapatan untuk lahan yang di tanami pohon dalam kisaran jumlah 250 - 1000 pohon. Penanaman di bawah 250 pohon menunjukkan dampak tidak menguntungkan sedangkan di atas 1000 pohon justru kurang menguntungkan. Hasil studi menunjukkan bahwa perbaikan pendapatan petani melalui mekanisme IJL untuk lahan yang di tanami pohon $<250,250-1000$ dan $>1000$ secara berurutan adalah $\cong-$ Rp. 18.000, 227.400 dan 62.000 (Hayati dkk. 2010). Pada awal penerapan IJL kisaran biaya yang 
dianggarkan oleh PT Krakatau Tirta Industri sebagai kompensasi adalah Rp. 1,20 - 1,7 juta (Amaruzaman \& Leimona 2015).

Sejauh ini pengaruh dari penerapan mekanisme IJL terhadap perbaikan ekonomi para petani peserta IJL masih belum nyata. Tampaknya untuk memberikan daya ungkit yang lebih besar bagi penerapan IJL agar menjadi lebih diterima oleh masyarakat petani adalah menginternalkan biaya terkait lahan.

\subsection{PERBAIKAN PENERAPAN IMBAL JASA LINGKUNGAN}

Imbal jasa lingkungan meskipun dalam beberapa kasus memiliki dampak perbaikan sosioekonomik dan fungsi ekologik namun keluaran (output) terkait dengan peningkatan kualitas sumberdaya manusia masih belum optimal, khususnya bagi masyarakat yang tergolong miskin (Mahanty et al. 2013). Hal ini dikarenakan dalam pelaksanaan mekanisme IJL peran petani lebih menekankan kepada proses pekerjaan seperti buruh dalam hal penanaman pohon. Oleh sebab itu untuk meningkatkan multiplier effect postif IJL yang lebih luas maka peningkatan mutu SDM petani perlu dipertimbangkan. Demikian pula penguatan kelembagaan juga menjadi kunci dalam keberhasilan pelaksanaan skema IJL (Laila dkk. 2014).

Selain itu terdapat sejumlah pendapat dari kelompok petani yang memandang pesimis bahwa skema IJL melalui upaya penanaman pohon dapat berdampak kepada perbaikan ekonomi petani. Pendapat ini muncul dengan fakta bahwa biaya hidup semakin meningkat seiring dengan waktu. Pada studi willingness to pay pada tahun 2004 (Van de Sand 2005) memberikan kompensasi oleh penerima manfaat (dalam hal ini PT Krakatau Tirta Industri) sebesar Rp. 1.200.000,- untuk setiap hektar lahan yang di tanam 500 pohon. Studi serupa lima tahun kemudian memberikan willingness to accept sebesar Rp. 2.528.490,- (Triani 2009). Bila diasumsikan kenaikan bersifat linier maka pada 2019 willingness to accept diduga menjadi lebih kurang Rp. 4.800.000,--. Analisis nilai ekonomi lahan juga dapat digunakan sebagi dasar dalam menimbangan peningkatan nilai IJL (Fahrizal 2009). Oleh sebab itu bila mekanisme IJL diperhitungkan dengan menimbang angka peningkatan biaya hidup maupun analisis nilai ekonomi lahan maka diperkirakan akan berjalan lebih kondusif.

\section{KESIMPULAN}

Penerapan mekanisme IJL memberikan sejumlah manfaat seperti munculnya kesadaran kelompok tani untuk menanam pohon lebih banyak (lebih dari 12500 pohon untuk lahan 25 ha). Terdapat indikasi peningkatan nilai sosioekonomik para peserta IJL walaupun belum terlihat nyata. Demikian pula dampak perbaikan fungsi ekologik belum terlihat nyata dikarenakan lahan yang ikut serta dalam mekanisme IJL tidak luas. Perlu strategi yang menimbang aspek kenaikan nilai kompensasi seiring waktu sehingga manfaat skema IJL bagi penyedia jasa dapat dirasakan. Penurunan erosi dan sedimentasi 
yang terjadi lebih berkorelasi dengan program perbaikan lingkungan oleh pemerintah daerah serta inisiatif penerima manfaat,

\section{DAFTAR PUSTAKA}

Amaruzaman S. \& B. Leimona. 2015. Seleksi imbal jasa lingkungan DAS Cidanau. Kiprah Agroforestry 2015. The World Agroforestry Centre. pp: 6-7

Amaruzaman S, N.P. Rahadian, B. Leimona. 2017. Role of intermediaries in the Payment for Environmental Services scheme: Lessons learnt in the Cidanau watershed, Indonesia. In: Co-investment in Ecosystem Services: Global Lessons from Payment and Incentive Schemes (Eds. S. Namirembe, B. Leimona, M. van Noordwijk, P. Minang). Chapter 35. World Agroforestry Centre (ICRAF). Nairobi. Kenya. pp: 1-15

Badan Pusat Statistik Kota Cilegon. 2019. Statistik industri Kota Cilegon

https://cilegonkota.bps.go.id/su bject/9/industri.html [Online, diunduh pada 9 Desember 2019]

DLHK Provinsi Banten. 2018. Ringkasan eksekutif Cagar Alam Rawa Danau. Dinas Lingkungan Hidup dan Kehutanan Provinsi Banten

Fahrizal A. 2009. Analisis nilai ekonomi lahan sebagai informasi bagi upaya peningkatan nilai pembayaran lingkungan.

Skripsi.

Departemen

Ekonomi

Sumberdaya dan Lingkungan. yakni PT Krakatau Tirta Industri, dalam upaya penanaman kembali lahan-lahan terdegradasi.

Fakultas Ekonomi dan Manajemen. Institut Pertanian Bogor

FKDC. (Tanpa Tahun). Innovative mechanism for integrated wastershed management in Cidanau. Forum Komunikasi DAS Cidanau (bahan presentasi)

Forum Komunikasi DAS Cidanau (FKDC). 2007. Banten Menuju Pengelolaan Terpadu DAS Cidanau. Rekonvasi Bhumi

Hartanto P. 2017. Perhitungan neraca air DAS Cidanau menggunakan metode Thronthwaite.Riset Geologi dan Pertambangan Vol. 27(2): 213-225

Hayati, G. Gunawan \& S. Sariyoga. 2010. Dampak pembayaran jasa lingkungan terhadap perkembangan agribisnis dan pendapatan rumah tangga petani. In: Prosiding Seminar Nasional Peningkatan Daya Saing Agribisnis Berorientasi Kesejahteraan Petani (Eds. K. Suradisastra, P. Simatupang \& B. Hutabarat). Pusat Analisis Sosial Ekonomi dan Kebijakan Pertanian. Kementerian Pertanian. pp: 341-347

Laila N, K. Murtilaksono \& B. Nugroho. 2014. Kelembagaan kemitraan hulu hilir untuk pasokan air DAS Cidanau, Provinsi Banten. Jurnal Penelitian Sosial dan Ekonomi Kehutanan Vol. 11(2): 137-152

Mahanty S., H. Suich \& L. Tacconi. 2013. Access and benefits in 
payments for environmental services and implications for REDD+: Lessons from seven PES schemes. Land Use Policy Vol.31:38-47

Megawanto R. 2018. Catatan konservasi

https://romeo90245.wordpress. com/2018/01/15/pembayaran-

jasa-lingkungan/ [Online, diunduh pada 13 Desember 2019]

Munawir \& S. Vermeulen. 2007. Fair deals for watershed services in Indonesia. Natural Resource Issues No. 9. International Institute for Environment and Development. London, UK

Namirembe S, B. Leimona, M. van Noordwijk, P. Minang. 2017. Co-investment in ecosystem services: global lessons from payment and incentive schemes. In: Co-investment in Ecosystem Services: Global Lessons from Payment and Incentive Schemes (Eds. S. Namirembe, B. Leimona, $\mathrm{M}$. van Noordwijk, P. Minang). Chapter 1. World Agroforestry Centre (ICRAF). Nairobi. Kenya. pp: 1-16

Pirard R., G. de Buren \& R. Lapeyre. 2014. Do PES improve the governance of forest restoration? Forest Vol. 5: 404424

Priyanto B. \& Titiresmi. 2006. Beberapa aspek pengelolaan Cagar Alam Gawa Danau sebagai sumber air baku. Jurnal Teknologi Lingkungan Vol. 7(3): 277-283

Rochmayanto Y. 2012. Peran hutan rakyat dalam mitigasi perubahan iklim sektor kehutanan. Pusat Penelitian dan Pengembangan Perubahan Iklim dan Kebijakan (Makalah pada Alih Teknologi Pusat Litbang Perubahan Iklim dan Kebijakan)

Suich H., M. Lugina, M.Z. Mutaqqin, I. Alviya \& G.K. Sari. 2017. Payments for ecosystem services in Indonesia. OryxThe International Journal of Conservation Vol. 51(3): 489497

Sutoyo. 2005. Model ketersediaan dan kebutuhan air kawasan Cilegon berbasis Daerah aliran Sungai Cidanau. Tesis Magister. Sekolah Pascasarjana Institut Pertanian Bogor

Tacconi L., S. Mahanty \& H. Suich. 2013. The livelihood impacts of payments for environmental services and implication for $R E D D_{+}$. Society and Natural Resources 26: 733-744

Triani A. 2009. Analisis willingness to accept masyarakat terhadap pembayaran jasa lingkungan DAS Cidanau (studi kasus Desa Citaman Kabupaten Serang). Skripsi. Departemen Ekonomi Sumberdaya dan Lingkungan. Fakultas Ekonomi dan Manajemen. Institut Pertanian Bogor

United Nations. No Year. World Water Day $22 \quad$ March https://www.un.org/en/events/w aterday/background.shtml [Online, diunduh pada 9 Desember 2019]

Van de Sand I. 2005. Assessing the Use of Environmental Service Payments as a Potential Adaptation Strategy to Climate 
Change in the Cidanau Vasseur L. \& R. Siron. 2019. Watershed, Banten, Indonesia.

Master Thesis. Department of Assessing ecosystem services Environmental Science and in UNESCO biosphere Technology. Imperial College. reserves. The Canadian London, UK

Commission for UNESCO 